\title{
The Information Content of Recommended Stocks by the Social Media
}

\author{
Yaling Lin \\ I-Shou University \\ Hsin-Yi Wang \\ National Sun Yat-sen University \\ Shih-Chi Shen \\ I-Shou University \\ Chih-Hsiung Chang \\ I-Shou University \\ Jui-Chu Tien \\ I-Shou University
}

Social media has developed rapidly in recent years. Many stock analysts utilize social media such as Facebook, Line and other community platforms to disseminate information to investors. This research explores the information content of recommended stock through social media by event study. The empirical result shows that analysts cannot provide significant abnormal returns to investors for listed company at stock exchange market. However, investors can get a little profit by day-trading within two days for listed company at over-the-counter market.

Keywords: Social Media, Information Content, Recommended Stock, Event Study.

\section{INTRODUCTION}

Whether investors can get extra return from information recommended by the media always caught the attention from the general public. However, the focus of related literature was always limited to traditional media (for example, the plane media and TV media), however, due to the popularity of modern technology and in the era of availability of handheld mobile device and convenience of network technology, social network has become one of the major sources for the general public to acquire information, therefore, the recommended information for many individual stocks acquired by retail investors from social network was usually difficult to distinguish its authenticity. Although investors in extensive work sites can get the information at any time through social network, yet information for stock market came from different sides, can the retail investors at the end of information distinguish the accuracy of the information correctly? In addition, lots of literature focused on the study of market 
response after the securities analyst had proposed the suggestion, Davies and Canes (1978) found that the public suggestion of the analyst will affect the market significantly for two days. Kim, Lin, J., and Slovin (1997) found that for the stock suggested by the analyst to buy in for 15 minutes before the opening of stock market, its price after stock market opening will be affected. Lin, Lin, and Wang (2009) had made empirical study to show that the investors of Taiwan's stock market can gain extra return when using the news or analysis suggestion announced by analyst in the media to operate the securities. Therefore, in this paper, focus will be on whether investors can get profit or not from the suggested information of the social network. In this paper, stocks recommended in social network (Facebook and LINE) in the period of January to May in 2017 was adopted as research samples, and event study method was used to observe the change of stock prices two weeks before and after the announcement of the information, and this was used to investigate the information content of recommended stocks in the social network.

\section{LITERATURE REVIEW}

Securities analysts or investment institutes in US usually made investment analysis report to be used as reference for the retail investors. In the newspaper or magazines, there were also special columns to report the view points and prediction on stocks from analysts. Davies and Canes (1978) had made special column study on "Heard on the Street" (HOTS) published daily by The Wall Street Journal, and the period was from 1970 to 1971 . The main objective was to investigate the correlation between stock price and the announced information, the following three conclusions were obtained: (1) To their customers, information provided by securities analyst had economic value. (2) Such information promotion did not bring sufficient adjustment of the stock price, that is, strong form efficient market hypothesis was not met. (3) The stock price adjustment of the recommended stock ended until the second day of the event, and this meant that can, through the information of special column of "Heard on the Street", gain extra return. Beneish (1991) had also studied the special column of "Heard on the Street" (HOTS), and it was thought that the analysts might be the traders of these stocks, or they might want to have their reputation enhanced through the report in the newspaper or magazine, therefore, there might be incentive for them to, release the information to HOTS first before they provided the information to private customers, therefore, the information announced by HOTS was not necessarily secondary information, and the average abnormal return one or two days before the event date and on the event date were all significant, when the recommended company had the release of surplus announcement information at the same time, then no matter it is recommendation for buying or selling the stock, there was usually significant response in the stock price, and the response was larger than other announced items. Davies and Canes (1978), Liu , Smith and Syed(1990) and Huth and Maris(1992), Bauman, W.S., S. Datta and M. E. Iskandar-Datta (1995) found that before the event date, there was significant abnormal return, in the meantime, higher transaction quantity was also accompanied, and this might be because the stocks recommended by analyst was popular stocks with hotter trading in recent days. Womack(1996) had used the special column of First Call to recommend and study the stock price response of recommended stocks, and the research period was from 1989 to 1990, and the empirical result of the study was as follows: (1) The stock recommended for buying showed an ascending stock price after the event date, and for the stock recommended for selling showed an descending stock price after the event date. (2) The stock price fluctuation of company of small scale was large than the stock of company of larger scale. (3) The stock price response of recommended stock had statistical meaning, however, after deduction of transaction cost, the recommended information did not have economic effectiveness.

To sum up, it was clear that most scholars emphasized on whether the recommended information of traditional media (for example, TV and newspaper and magazine) was beneficial to the investors, but in this article, the focus was on the information content of the stocks recommended from social network. 


\section{METHODOLOGY}

In this study, Taiwan's stock market was taken as example, and a total of 123 samples were taken, meanwhile, the samples were divided into 68 listed stocks at the stock exchange market and 55 listed stocks at the over-the-counter market, and event study method was used to investigate each model and to verify the difference of its abnormal return. Although sample data were collected from Facebook and Line, for example, stock information recommended from social networks such as "stock market talent Cheng Jui-Tsung", "Little Danny investment team", "Hsiao Lu's investment diary", "Hot and popular stocks", "Boring Chan stock information web" and "Brother Lung's stocks and futures", then the daily data according to the event date was registered one by one into Taiwan Economic Journal (TEJ), then Event Study method was used to run the data in sequence to inspect if there was abnormal return in the data of individual stock.

The main purpose of event study method was, for special event, to investigate if it will cause abnormal return to the securities. In this article, focus was put on the information announcement of individual securities. There was no certain standard for the event date and estimation date but it was dependent on the research characteristic. In this article, event date was $t=0$, that is, it was the date that the stock was recommended in social network, in order to understand the stock price change before and after the event date, and to avoid the influence of other factors by too long event period, therefore, 10 days $(\mathrm{t}=$ 10 10) before and after the event date were taken as event windows. In addition, in order to set up evaluation standard for abnormal return, it was needed to get the expected return of pre-event estimation period, in that period, it was not affected or interfered by special event, and it can facilitate reasonable expected return estimation, and in this article, 200 days $(\mathrm{t}=-220 \sim-21)$ before will be taken as estimation period.

The research models included average adjustment model, market adjusted return model and GARCH estimation method.

\section{MEAN ADJUSTED RETURN MODEL}

In that model, it defined the sample mean number of estimated period return rate of securities $\mathrm{j}$ as $R_{j}$, then the expected return rate of $t$ term of event period was:

$E\left(R_{j t}\right)=R_{j}$

\section{MARKET ADJUSTED RETURN MODEL}

In that model, the return rate of $\mathrm{t}$ term of market as $R_{m t}$, then the expected return rate of $\mathrm{t}$ term of event period was:

$E\left(R_{j t}\right)=R_{m t}$

\section{GARCH MODEL}

$R_{j t}=\alpha_{j}+\beta_{j} R_{m t}+\varepsilon_{j t}$

$\varepsilon_{j t} \mid \Psi_{t-1} \sim N\left(0, h_{j t}\right)$

$h_{j t}=\omega_{j}+\delta_{j} h_{j t-1}+\gamma_{j} \varepsilon_{j t-1}^{2}$ 
wherein, $\omega_{j}>0 . \quad \delta_{j} \geq 0$ and $\gamma_{j}>0, \Psi_{t-1}$ was information collection before achieving $\mathrm{t}$ term, $h_{j t}$ was conditional heteroskedasticity of $\mathrm{t}$ term, and was $\mathrm{N}(\cdot)$ normal distribution. To satisfy the model to be a stable sequence, $\operatorname{Var}\left(\varepsilon_{j t}\right)<\infty$ and $\gamma_{j}+\delta_{j}<1$ must be satisfied. When estimating the parameters, Maximum Likelihood Estimation was used.

\section{EMPIRICAL RESULT}

The empirical results are mainly divided into three modes for listed company at stock exchange market (mean adjusted model, market adjusted model and GARCH Model) and two modes for listed company at over-the-counter market (mean adjusted model and market adjusted model). According to these models, we discuss abnormal returns by event study.

TABLE 1

MEAN ADJUSTED MODEL- STOCKS LISTED IN STOCK EXCHANGE MARKET

\begin{tabular}{|c|c|c|c|c|c|}
\hline $\mathrm{t}$ & $\begin{array}{c}\text { Abnormal } \\
\text { Return (AR) }\end{array}$ & $\begin{array}{c}\text { Cross-Sectional } \\
\text { Statistics }\end{array}$ & Prob.Value & $\begin{array}{c}\text { Non-parameter } \\
\text { Statistics }\end{array}$ & Prob.Value \\
\hline-10 & 0.2801 & 0.7469 & 0.4551 & 0.5388 & 0.5900 \\
\hline-9 & -0.0968 & -0.2746 & 0.7836 & -0.1796 & 0.8575 \\
\hline-8 & -0.7071 & -2.2346 & $0.0254^{* *}$ & -2.3349 & $0.0196^{* *}$ \\
\hline-7 & 0.4852 & 1.1050 & 0.2692 & 0.1796 & 0.8575 \\
\hline-6 & 0.8310 & 1.4764 & 0.1398 & 0.5388 & 0.5900 \\
\hline-5 & -0.0830 & -0.2479 & 0.8042 & -1.2572 & 0.2087 \\
\hline-4 & 0.5496 & 1.3686 & 0.1711 & 1.2572 & 0.2087 \\
\hline-3 & 0.7012 & 1.2653 & 0.2058 & 1.2572 & 0.2087 \\
\hline-2 & 1.4617 & 2.7772 & $0.0055^{* * *}$ & 1.6164 & 0.1060 \\
\hline-1 & 1.5797 & 3.7436 & $0.0002^{* * *}$ & 2.3349 & $0.0196^{* *}$ \\
\hline 0 & 2.7354 & 4.0443 & $0.0001^{* * *}$ & 2.6941 & $0.0071^{* * *}$ \\
\hline 1 & 1.4317 & 2.2405 & $0.0251^{* *}$ & 1.2572 & 0.2087 \\
\hline 2 & -0.3782 & -0.7418 & 0.4582 & -0.898 & 0.3692 \\
\hline 3 & -0.0717 & -0.2090 & 0.8345 & -0.1796 & 0.8575 \\
\hline 4 & 0.1858 & 0.3763 & 0.7067 & -0.1796 & 0.8575 \\
\hline 5 & -1.0036 & -2.6275 & $0.0086^{* * *}$ & -2.6941 & $0.0071^{* * *}$ \\
\hline 6 & -0.0688 & -0.1434 & 0.8860 & -0.5388 & 0.5900 \\
\hline 7 & 0.6188 & 1.3336 & 0.1823 & 0.1796 & 0.8575 \\
\hline 8 & 0.3170 & 0.5484 & 0.5834 & 1.2572 & 0.2087 \\
\hline 9 & -0.1278 & -0.3473 & 0.7284 & -0.8980 & 0.3692 \\
\hline 10 & -0.1924 & -0.5473 & 0.5842 & -0.8980 & 0.3692 \\
\hline
\end{tabular}

$\mathrm{t}=0$ represents the event date, that is, it was the date that the stock was recommended in social network. $\mathrm{t}=-10$ and $\mathrm{t}=10$ represent 10 days before and after the event, respectively. ${ }^{*}$ indicates significant at $10 \%, * *$ indicates significant at $5 \%$, and $* * *$ indicates significant at $1 \%$.

Table 1 shows the results of "Mean Adjusted Model - stocks listed in stock exchange market" sample. Cross sectional statistics and symbolic method statistics had quite high consistence, and significance can be seen respectively at $\mathrm{t}=-8 .-1.0 .5$ days, meanwhile, it was found that for the mean abnormal return one day before the event date and on the event date, high positive abnormal return can be seen. Therefore, it the investors believed this information, the room to get profit was limited.

In Table 2, the sample of "Market Adjusted Model - stocks listed in stock exchange market", full consistent test results cannot be seen between two statistical test methods. Where for the cross-sectional 
statistics, the significant abnormal return appeared on $-8,-6,-2,-1,0,1,5,7$ days of the event date; for the sign test, they appeared on $-5,-4,-1,0,5$ days of the event date. From the data in the table, it can be seen that $1 \sim 2$ days before and after the event date, the significance was almost the same as that of mean adjusted model.

\section{TABLE 2 \\ MARKET ADJUSTED RETURN MODEL - STOCKS LISTED IN STOCK EXCHANGE MARKET}

\begin{tabular}{|c|c|c|c|c|c|}
\hline $\mathrm{t}$ & $\begin{array}{c}\text { Abnormal } \\
\text { Return (AR) }\end{array}$ & $\begin{array}{c}\text { Cross-Sectional } \\
\text { Statistics }\end{array}$ & Prob.Value & $\begin{array}{c}\text { Non-parameter } \\
\text { Statistics }\end{array}$ & Prob.Value \\
\hline-10 & 0.1869 & 0.5295 & 0.5965 & 0.1796 & 0.8575 \\
\hline-9 & -0.0682 & -0.2147 & 0.8300 & -0.5388 & 0.5900 \\
\hline-8 & -0.6757 & -2.1826 & $0.0291^{* *}$ & -1.6164 & 0.1060 \\
\hline-7 & 0.6576 & 1.4993 & 0.1338 & 1.2572 & 0.2087 \\
\hline-6 & 0.9625 & 1.6848 & $0.092^{*}$ & 0.5388 & 0.5900 \\
\hline-5 & -0.2117 & -0.6430 & 0.5202 & -2.3349 & $0.0196^{* *}$ \\
\hline-4 & 0.6370 & 1.5190 & 0.1288 & 2.3349 & $0.0196^{* *}$ \\
\hline-3 & 0.6820 & 1.2991 & 0.1939 & 1.2572 & 0.2087 \\
\hline-2 & 1.4255 & 2.7851 & $0.0054^{* * *}$ & 1.2572 & 0.2087 \\
\hline-1 & 1.4944 & 3.3179 & $0.0009^{* * *}$ & 2.3349 & $0.0196^{* *}$ \\
\hline 0 & 2.9703 & 4.4031 & $0 *$ & 3.4125 & $0.0006^{* * *}$ \\
\hline 1 & 1.4751 & 2.3104 & $0.0209^{* *}$ & 0.8980 & 0.3692 \\
\hline 2 & -0.3878 & -0.7487 & 0.4541 & -1.2572 & 0.2087 \\
\hline 3 & 0.1155 & 0.3594 & 0.7193 & -0.1796 & 0.8575 \\
\hline 4 & 0.3833 & 0.8361 & 0.4031 & 0.5388 & 0.5900 \\
\hline 5 & -0.9642 & -2.7072 & $0.0068^{* * *}$ & -1.9757 & $0.0482^{* *}$ \\
\hline 6 & 0.1973 & 0.4135 & 0.6792 & -0.1796 & 0.8575 \\
\hline 7 & 0.8704 & 1.8460 & $0.0649^{*}$ & 0.8980 & 0.3692 \\
\hline 8 & 0.2884 & 0.5184 & 0.6042 & 0.5388 & 0.5900 \\
\hline 9 & 0.2398 & 0.6468 & 0.5178 & 0.1796 & 0.8575 \\
\hline 10 & -0.0296 & -0.0857 & 0.9317 & -1.2572 & 0.2087 \\
\hline
\end{tabular}

$\mathrm{t}=0$ represents the event date, that is, it was the date that the stock was recommended in social network. $\mathrm{t}=-10$ and $\mathrm{t}=10$ represent 10 days before and after the event, respectively. ${ }^{*}$ indicates significant at $10 \%$, ** indicates significant at $5 \%$, and $* * *$ indicates significant at $1 \%$. 
TABLE 3

GARCH MODEL - STOCKS LISTED IN STOCK EXCHANGE MARKET

\begin{tabular}{|c|c|c|c|c|c|}
\hline $\mathrm{t}$ & $\begin{array}{c}\text { Abnormal } \\
\text { Return (AR) }\end{array}$ & $\begin{array}{c}\text { Cross-Sectional } \\
\text { Statistics }\end{array}$ & Prob.Value & $\begin{array}{c}\text { Non-parameter } \\
\text { Statistics }\end{array}$ & Prob.Value \\
\hline-10 & 0.2301 & 0.5146 & 0.6069 & 0.5774 & 0.5637 \\
\hline-9 & 0.0708 & 0.1548 & 0.8769 & -0.1925 & 0.8474 \\
\hline-8 & -0.7705 & -1.6588 & $0.0972^{*}$ & -1.7321 & $0.0833^{*}$ \\
\hline-7 & 0.4759 & 1.0118 & 0.3117 & 0.5774 & 0.5637 \\
\hline-6 & 0.7077 & 1.4891 & 0.1365 & 0.5774 & 0.5637 \\
\hline-5 & -0.1112 & -0.2327 & 0.8160 & -2.117 & $0.0343^{* *}$ \\
\hline-4 & 0.6015 & 1.2515 & 0.2108 & 1.3472 & 0.1779 \\
\hline-3 & 0.5803 & 1.2026 & 0.2291 & 1.3472 & 0.1779 \\
\hline-2 & 1.4267 & 2.9478 & $0.0032^{* * *}$ & 1.3472 & 0.1779 \\
\hline-1 & 1.7348 & 3.5755 & $0.0003^{* * *}$ & 2.8868 & $0.0039^{* * *}$ \\
\hline 0 & 2.7328 & 5.6245 & $0 *$ & 3.2717 & $0.0011^{* * *}$ \\
\hline 1 & 1.4045 & 2.8846 & $0.0039^{* * *}$ & 0.1925 & 0.8474 \\
\hline 2 & -0.7841 & -1.6081 & 0.1078 & -0.9623 & 0.3359 \\
\hline 3 & -0.2553 & -0.5233 & 0.6008 & -0.5774 & 0.5637 \\
\hline 4 & 0.1935 & 0.3961 & 0.6920 & 0.1925 & 0.8474 \\
\hline 5 & -0.9088 & -1.8595 & $0.0630^{*}$ & -2.1170 & $0.0343^{* *}$ \\
\hline 6 & 0.2533 & 0.5180 & 0.6044 & 0.1925 & 0.8474 \\
\hline 7 & 0.6550 & 1.3381 & 0.1809 & 0.9623 & 0.3359 \\
\hline 8 & 0.1624 & 0.3315 & 0.7402 & 0.5774 & 0.5637 \\
\hline 9 & 0.2034 & 0.4150 & 0.6781 & -0.1925 & 0.8474 \\
\hline 10 & 0.0401 & 0.0818 & 0.9348 & -0.5774 & 0.5637 \\
\hline
\end{tabular}

$\mathrm{t}=0$ represents the event date, that is, it was the date that the stock was recommended in social network. $\mathrm{t}=-10$ and $\mathrm{t}=10$ represent 10 days before and after the event, respectively. ${ }^{*}$ indicates significant at $10 \%, * *$ indicates significant at $5 \%$, and $* * *$ indicates significant at $1 \%$.

Table 3 lists the sample of "GARCH Model- stocks listed in stock exchange market". Cross sectional statistics showed abnormal return on $\mathrm{t}=-8,-2,-1,0,1,5$ days; for sign test, abnormal return appeared on $8,-5,-1,0,5$ days. In such model, it was similarly found that one day before event date and on the event date, there was high positive abnormal return. 
TABLE 4

MEAN ADJUSTED MODEL- STOCKS LISTED IN OVER-THE-COUNTER MARKET

\begin{tabular}{|c|c|c|c|c|c|}
\hline $\mathrm{t}$ & $\begin{array}{c}\text { Abnormal } \\
\text { Return (AR) }\end{array}$ & $\begin{array}{c}\text { Cross-Sectional } \\
\text { Statistics }\end{array}$ & Prob.Value & $\begin{array}{c}\text { Non-parameter } \\
\text { Statistics }\end{array}$ & Prob.Value \\
\hline-10 & -0.7421 & -1.5803 & 0.1140 & -0.8528 & 0.3938 \\
\hline-9 & -0.1332 & -0.2150 & 0.8298 & 0.4264 & 0.6698 \\
\hline-8 & 0.4029 & 1.1570 & 0.2473 & 1.7056 & $0.0881^{*}$ \\
\hline-7 & -0.5345 & -1.2265 & 0.2200 & -1.2792 & 0.2008 \\
\hline-6 & 0.4904 & 1.1694 & 0.2423 & 0.8528 & 0.3938 \\
\hline-5 & -0.3605 & -0.6918 & 0.4891 & 0.8528 & 0.3938 \\
\hline-4 & 0.3015 & 0.6242 & 0.5325 & -1.2792 & 0.2008 \\
\hline-3 & 1.4205 & 2.8194 & $0.0048^{* * *}$ & 2.9848 & $0.0028^{* * *}$ \\
\hline-2 & 2.1553 & 3.0876 & $0.0020^{* * *}$ & 2.9848 & $0.0028^{* * *}$ \\
\hline-1 & 1.1936 & 2.3141 & $0.0207^{* *}$ & 0.4264 & 0.6698 \\
\hline 0 & 2.6670 & 2.6934 & $0.0071^{* * *}$ & 2.1320 & $0.033^{* *}$ \\
\hline 1 & 0.4759 & 0.7825 & 0.4339 & -0.8528 & 0.3938 \\
\hline 2 & 0.4583 & 1.1219 & 0.2619 & 0.4264 & 0.6698 \\
\hline 3 & 1.1242 & 1.8308 & $0.0671 *$ & 1.2792 & 0.2008 \\
\hline 4 & -0.9160 & -2.0822 & $0.0373^{* *}$ & -1.7056 & $0.0881^{*}$ \\
\hline 5 & -0.3741 & -0.5507 & 0.5818 & -0.4264 & 0.6698 \\
\hline 6 & 0.0923 & 0.1359 & 0.8919 & -0.8528 & 0.3938 \\
\hline 7 & -0.2091 & -0.3429 & 0.7317 & -0.4264 & 0.6698 \\
\hline 8 & -0.268 & -0.5629 & 0.5735 & -0.4264 & 0.6698 \\
\hline 9 & -0.4284 & -1.1834 & 0.2366 & -1.2792 & 0.2008 \\
\hline 10 & -0.2210 & -0.3875 & 0.6984 & -0.4264 & 0.6698 \\
\hline
\end{tabular}

$\mathrm{t}=0$ represents the event date, that is, it was the date that the stock was recommended in social network. $\mathrm{t}=-10$ and $\mathrm{t}=10$ represent 10 days before and after the event, respectively. ${ }^{*}$ indicates significant at $10 \%$, $* *$ indicates significant at $5 \%$, and $* * *$ indicates significant at $1 \%$.

In sample of "Mean Adjusted Model - stocks listed in over-the-counter market" (Table 4), pretty high consistence can be seen for two statistical test methods, in the event windows of a total of 21 days before and after the event date, significance can be seen respectively on $-3,-2,0,4$ days, from the data in the table, it can be seen that two days before the event date and on the event date, the significance of mean abnormal return was high. 


\section{TABLE 5}

MEAN ADJUSTED RETURN MODEL - STOCKS LISTED IN OVER-THE-COUNTER MARKET

\begin{tabular}{|c|c|c|c|c|c|}
\hline $\mathrm{t}$ & $\begin{array}{c}\text { Abnormal } \\
\text { Return (AR) }\end{array}$ & $\begin{array}{c}\text { Cross-Sectional } \\
\text { Statistics }\end{array}$ & Prob.Value & $\begin{array}{c}\text { Non-parameter } \\
\text { Statistics }\end{array}$ & Prob.Value \\
\hline-10 & 0.0252 & 0.0737 & 0.9412 & 0.6742 & 0.5002 \\
\hline-9 & 0.2175 & 0.6944 & 0.4874 & 0.1348 & 0.8927 \\
\hline-8 & 0.7224 & 1.931 & $0.0535^{*}$ & -0.4045 & 0.6858 \\
\hline-7 & 0.7691 & 2.3404 & $0.0193^{* *}$ & 1.4832 & 0.1380 \\
\hline-6 & 0.3831 & 1.2800 & 0.2005 & 0.1348 & 0.8927 \\
\hline-5 & 0.3157 & 1.1099 & 0.2670 & 2.0226 & $0.0431^{* *}$ \\
\hline-4 & 0.1681 & 0.4774 & 0.6331 & 0.4045 & 0.6858 \\
\hline-3 & 1.2353 & 3.1007 & $0.0019^{* * *}$ & 2.8316 & $0.0046^{* * *}$ \\
\hline-2 & 1.5860 & 3.6117 & $0.0003^{* * *}$ & 2.2923 & $0.0219^{* *}$ \\
\hline-1 & 1.0959 & 3.0853 & $0.002^{* * *}$ & 0.9439 & 0.3452 \\
\hline 0 & 1.9941 & 3.8523 & $0.0001^{* * *}$ & 1.4832 & 0.1380 \\
\hline 1 & 0.7693 & 1.8423 & $0.0654^{*}$ & -0.6742 & 0.5002 \\
\hline 2 & 0.4481 & 1.3181 & 0.1875 & -0.4045 & 0.6858 \\
\hline 3 & 0.3549 & 0.9465 & 0.3439 & -0.1348 & 0.8927 \\
\hline 4 & -0.0580 & -0.2095 & 0.8341 & 0.1348 & 0.8927 \\
\hline 5 & -0.5202 & -1.4535 & 0.1461 & -1.7529 & $0.0796^{*}$ \\
\hline 6 & -0.0100 & -0.0285 & 0.9773 & -1.2136 & 0.2249 \\
\hline 7 & -0.4347 & -1.4569 & 0.1451 & -1.4832 & 0.1380 \\
\hline 8 & -0.2819 & -0.9340 & 0.3503 & -0.9439 & 0.3452 \\
\hline 9 & 0.0914 & 0.2835 & 0.7768 & -1.2136 & 0.2249 \\
\hline 10 & -0.3721 & -1.2302 & 0.2186 & -2.2923 & 0.0219 \\
\hline
\end{tabular}

$\mathrm{t}=0$ represents the event date, that is, it was the date that the stock was recommended in social network. $\mathrm{t}=-10$ and $\mathrm{t}=10$ represent 10 days before and after the event, respectively. ${ }^{*}$ indicates significant at $10 \%$, ** indicates significant at $5 \%$, and $* * *$ indicates significant at $1 \%$.

In sample of "Market Adjusted Return Model - stocks listed in over-the-counter market" (Table 5), cross sectional statistics and sigh test statistics did not have full consistent test result, and 1 2 days before the event date, the return rate showed a descending trend, because the stock price will get up and down, for a short term, the main trend of fluctuation of the return rate showed an ascending trend, when it was compared to different models for stock exchange market, more profit room can be seen.

\section{CONCLUSION}

Most investors cannot get profit from the recommendation information in social network, and the analysis results for stock exchange market and over-the-counter market were quite consistent. In the stock exchange market, investors almost did not have any room to get profit; but for the over-the-counter market, there was tiny room to get profit, however, since Taiwan's stock market was of $\mathrm{T}+2$ transaction system, investors might not have enough time to use such recommended information, therefore, for the general transaction, there was no room to get profit, unless you did the day trading or the next-day trading. No matter it was stock exchange market or over-the-counter market sample, five business days before the event date, the average abnormal return showed significant positive response, however, after the event date, the average abnormal return showed significant descending, for these phenomena, it was thought to be due to the following reasons: 
1. The recommender had stocks in his/her hand, and the recommender hoped to use such information to raise the stock price higher.

2. The recommender did not have stocks, the recommender purely recommended the investors to buy in based on the past trend of certain stock.

3. There was already insider trading for the stock before the event date.

In short, it was thought that most of the information recommended in social network cannot let investors get profit stably.

\section{REFERENCES}

Bauman, W. S., Datta. S., \& Iskandar- Datta, M. E. (1995). Investment analyst recommendations: A test of the announcement effect and the valuable information effect. Journal of Business Finance and Accounting, 22(5), 659-670.

Davies, P. L., \& Canes, M. (1978). Stock prices and the publication of second-hand information. Journal of Business, 51(1), 43-55.

Huth, W. L., \& Maris, B. A. (1992). Large and small firm stock price response to "Heard On The Street" recommendation. Journal of Accounting, Auditing \& Finance, 7(1), 27-47.

Kim, S., Lin, J., \& Slovin, M. (1997). Market structure, informed trading, and analyst's recommendations. Journal of Quantitative Analysis, 32(4), 507-524.

Lin, C.C., Lin, F.T., \&Wang, Y.H. (2009). Can investors profit from the stock recommendations on the journalism? Testing conditional heteroscedasticity in the market model. International Research Journal of Finance and Economics, 33, November, 111-119.

Liu, P., Stanley D. S., \& Aznat A. S. (1990). Stock Price Reactions to the Wall Street Journal's Securities Recommendations. Journal of Financial and Quantitative Analysis, 25(3), 399-410.

Womack, K. L. (1996). Do brokerage analyst's recommendations have investment value? Journal of Finance, 51(1), 137-167. 